\title{
RESULTADOS TIMPANOMÉTRICOS: LACTENTES DE SEIS MESES DE IDADE
}

\section{Timpanometric findings: six-month-old infants}

\author{
Juliana Jandre Melo ${ }^{(1)}$, Dóris Ruth Lewis ${ }^{(2)}$, Luciana Lozza de Moraes Marchiori ${ }^{(3)}$
}

\begin{abstract}
RESUMO
Objetivo: verificar os achados timpanométricos em lactentes de seis meses de idade, sendo ou não amamentados com aleitamento materno exclusivo e/ou predominante. Métodos: foram avaliados 46 lactentes que estavam com seis meses na data da avaliação, sendo que $30(61,22 \%)$ lactentes estavam sendo submetidos à amamentação exclusiva por um período mínimo de seis meses e 16 $(34,78 \%)$ lactentes não estavam em aleitamento exclusivo. Os lactentes foram submetidos à inspeção do meato acústico externo e a realização da timpanometria. Resultados: houve diferença estatisticamente significante $(p=0,0084)$ nos achados de alteração timpanométrica em lactentes amamentados por mais tempo. Em relação ao sexo dos lactentes relacionados ao tempo de amamentação, apenas o masculino apresentou resultados estatisticamente significantes $(p=0,0006)$ em relação ao fator de proteção de curvas timpanométricas normais. Em relação aos outros fatores analisados, não foi possível encontrar relação entre tempo de amamentação exclusiva e alterações timpanométricas. Conclusão: apesar de existirem outros fatores de risco, a amamentação exclusiva por um período de seis meses, atua como um fator de proteção contra alterações timpanométricas, não necessitando da introdução de outros alimentos antes deste período recomendado como ideal pela Organização Mundial de Saúde.
\end{abstract}

DESCRITORES: Aleitamento Materno; Orelha Média; Otite; Lactente

\section{INTRODUÇÃO}

O leite humano, além de seus componentes nutritivos, contém, em sua composição, uma complexidade de células e moléculas que atuam na proteção do recém-nascido e proporciona um mecanismo de regulação dos transportadores transmembrana. $\mathrm{Na}$ mulher em lactação, o sistema denominado enteromamário ou broncomamário atua quando os patógenos (bactérias) entram em contato com as mucosas do intestino ou aparelho respiratório e são fagocitados pelos macrófagos. Com isso, desencadeia-se uma ação estimulante nos linfócitos $\mathrm{T}$, promovendo

(1) Fonoaudióloga; Universidade Norte do Paraná; Mestre em Fonoaudiologia pela Pontifícia Universidade Católica de São Paulo.

(2) Fonoaudióloga; Pontifícia Universidade Católica de São Paulo; Doutora em Saúde Pública pela Universidade de São Paulo.

(3) Fonoaudióloga; Universidade Norte do Paraná; Doutora em Medicina e Ciências da Saúde pela Universidade Estadual de Londrina. diferenciação dos linfócitos $B$ produtores de imunoglobulinas A $(\lg A)$. Os linfócitos migram para a glândula mamária e, com a mediação de citocinas, tornam-se células plasmáticas que produzem uma glicoproteína que é acoplada à IgA, convertendose em imunoglobulina A secretória (IgAs). Esta é uma função importante e específica de proteção do recém-nascido conferida pelo leite humano ${ }^{1,2}$.

A Organização Mundial de Saúde (OMS) ${ }^{3}$ adota as seguintes categorias de aleitamento materno:

- Aleitamento materno exclusivo: quando a criança recebe somente leite materno, diretamente da mama ou extraído, e nenhum outro líquido ou sólido, com exceção de gotas ou xaropes de vitaminas, minerais e/ou medicamentos;

- Aleitamento materno predominante: quando o lactente recebe leite materno, diretamente da mama ou extraído, água ou bebidas à base de água, como sucos de frutas ou chás;

- Aleitamento materno misto: quando a criança recebe leite materno, diretamente do seio ou extraído, além de receber qualquer leite de vaca fresco ou em pó. 
O aleitamento materno é um fator importante para a imunização das infecções de orelha média (otites). A disponibilidade de nutrientes do leite materno, seu conteúdo em substâncias imunológicas e sua qualidade quanto à higiene, o tornam fundamental para a saúde e desenvolvimento da criança ${ }^{4}$.

A Organização Mundial da Saúde (OMS) ${ }^{3}$ considera o leite materno como alimento ideal para os recém-nascidos. Suas principais recomendações quanto ao aleitamento são: apoio e incentivo ao aleitamento materno; início da amamentação tão cedo quanto possível; mamadas sob livre demanda, ou seja, sem horários pré-fixados e que nenhum suplemento é necessário a bebês amamentados com leite materno até seis meses de idade.

Segundo a American Academy of Pediatrics, o leite materno propicia uma nutrição e proteção imunológica excelentes para os recém nascidos, sendo que o aleitamento materno deve ser oferecido até 4-6 meses de forma exclusiva e complementada com outros alimentos até pelo menos os 12 meses de idade ${ }^{5}$.

O leite materno possui a capacidade de inibir o crescimento de vários tipos de bactérias, tendo importante papel contra a colonização bacteriana nasofaríngea e conseqüentemente contra a instalação de processos infecciosos de orelha média, o que faz que a criança obtenha o feed-back auditivo necessário. É por meio deste feed-back estabelecido entre a fala e a audição que o indivíduo adquire as suas referências auditivas, as quais somadas aos símbolos lingüísticos, ajudam a formar os conceitos básicos à construção da linguagem, função cerebral que apresenta um caráter eminentemente social. Essa linguagem, organizada em inúmeros processos neuropsicológicos orgânicos (especialmente o auditivo) e afetivos, propicia o aprendizado do simbólico, sendo assim de imensa importância durante todo o processo educacional ${ }^{6}$.

O resultado timpanométrico, utilizado principalmente para identificar patologias de orelha média na população pediátrica (imitanciometria), pode ser utilizado como um importante identificador dessas possíveis alterações, possibilitando um diagnóstico precoce, fundamental para evitar um quadro clínico crônico ${ }^{6,7}$.

Pesquisadores ${ }^{8,9}$ salientaram que crianças em aleitamento materno apresentam menores índices de diarréia quando comparadas aos seus pares que foram alimentados com outros tipos de alimentos, como as fórmulas. Estes ainda teriam menores recorrências de infecções respiratórias e de orelha média. Além disso, a criança que continua em aleitamento materno, durante uma infecção, recuperase mais rapidamente.
Nesta pesquisa pretendeu-se verificar os achados timpanométricos em lactentes de seis meses de idade, sendo ou não amamentados com aleitamento materno exclusivo e/ou predominante.

\section{MÉTODOS}

Devido à idade dos lactentes em estudo, a Clínica Universitária da Universidade Estadual de Londrina foi selecionada para a coleta de dados da pesquisa, devido ao fácil acesso e por conter um grande número de lactentes na idade escolhida.

Foi realizado um levantamento de todos os lactentes cadastrados na Bebê Clínica - Universidade Estadual de Londrina, que estavam com seis meses na data da avaliação, no período de novembro de 2003 a janeiro de 2004. Obteve-se uma relação contendo 62 pacientes cadastrados nesse período, dos quais, dez foram excluídos por não morarem na cidade de Londrina. Após esse levantamento, manteve-se contato com todos os responsáveis das crianças, a fim de agendar o dia e horário para o procedimento de coleta de dados. Obteve-se um total de quarenta e seis lactentes interessados em participar da pesquisa, sendo 22 do sexo feminino e 24 do masculino, os quais foram submetidos à inspeção do meato acústico externo e a timpanometria.

Foram excluídos deste estudo dois lactentes que apresentaram algum fator que impedisse a realização do procedimento e/ou apresentaram risco para a deficiência auditiva ${ }^{10}$ (Figura 1).

Participaram da pesquisa 46 mães, caracterizadas quanto à idade e nível de escolaridade. Tais dados foram coletados por meio de entrevista realizada pela autora com as mães e/ou responsáveis de cada lactente os quais estão citados a seguir:

\section{Identificação:}

- Nome da criança, sexo, data de nascimento, freqüenta creche (qual e período).

- Cidade, estado, endereço e telefone.

- Nome da mãe, idade, profissão e nível escolar.

- Nome do pai, idade, profissão e nível escolar.

- Recebimento médio mensal familiar (salário mínimo) segundo IBGE.

- Ordem gestacional.

- Contato com tabagismo (durante a gestação ou no período pós - natal de forma passiva).

\section{Indicadores de risco para deficiência \\ Auditiva:}

- História familiar de perda auditiva na infância?

- Suspeita dos familiares de atraso no desenvolvimento de fala, linguagem e audição?

- Otite média recorrente ou persistente, com efusão por pelo menos três meses? 
- Neonatos (recém-nascidos) que ficaram mais de 48 horas na UTI neonatal?

- Infecções no período neonatal?

- Infecções no período pós-natal associadas a perdas auditivas sensorioneurais, incluindo a meningite?

- Anomalias craniofaciais incluindo as alterações morfológicas de pavilhão auricular e meato acústico externo?

- Hiperbilirrubinemia com exsanguíneo-transfusão?

- Ventilação mecânica por período > 5 dias?

- Síndromes associadas a alterações auditivas?

- Desordens neurovegetativas ou neuropatias sensório-motoras?

\section{Amamentação}

- Tempo de amamentação exclusiva ou predominante:

- Atual tipo de amamentação: (exclusiva, predominante, mista e artificial)

- Época da introdução de outros alimentos?

- Época do desmame total?

Após a assinatura da "Carta de Consentimento Informado", foi aplicado questionário com as mães e/ou responsáveis: para a caracterização da população estudada (dados pessoais e familiares, se o lactente estava ou não institucionalizado e fumo) e o tipo de aleitamento a que cada lactente estava sendo submetido, até o período da avaliação.

Por meio da Inspeção do Meato Acústico Externo as pesquisadoras puderam observar se 0 lactente estava apto para realizar a timpanometria, como também observar o formato e o tamanho do meato acústico externo para a escolha adequada da sonda, com a finalidade de se obter uma boa vedação da orelha durante a avaliação;

- A timpanometria foi realizada para avaliar a mobilidade do conjunto tímpano - ossicular, através da variação de pressão manual de +200 daPa a -200 daPa. Foi medido o volume das orelhas externa e média, onde, em determinado ponto de variação de pressão do meato acústico externo, foi obtido o ponto de máxima compliância do sistema tímpano-ossicular. A diferença encontrada entre as duas medidas forneceu o volume da orelha média ou a imitância absoluta do sistema. O procedimento descrito acima foi realizado utilizando a freqüência da sonda de $226 \mathrm{~Hz}$ e foram feitas três repetições da variação de pressão para se descartar a possibilidade de erro durante a análise. Os lactentes foram testados recostados no colo da mãe ou da estagiária, onde foi desmembrada a sonda do conjunto de cabeça para que a mesma ficasse livre. Tanto nessa fase, como na anterior, foi necessário o auxilio de duas pessoas, pois, enquanto uma mantinha a sonda na orelha do lactente, a outra o distraía com um brinquedo para a realização do exame. Para a análise dos resultados, foram consideradas curvas timpanométricas normais as do tipo "A" e as alteradas do tipo "B" e "C" 11,12.

- A Inspeção do Meato Acústico Externo foi feita com um otoscópio a pilha da marca Kole, enquanto que os demais procedimentos foram realizados com um Impedance audiometer AZ7 (manual), calibrado em 12/04/2003 da Interacoustics.

O projeto foi aprovado e analisado pela Comissão de Ética da UNOPAR sob protocolo número 0213/03.

$\mathrm{Na}$ análise estatística dos resultados, utilizamos os testes Qui-quadrado com correção de Yates e o Exato de Fisher (usado quando o valor esperado em alguma casela na tabela 2X2 menor que 5). 0 estudo foi realizado nas seguintes categorias:

- Influência do tempo de amamentação exclusiva e/ou predominante para as alterações timpanométricas;

- Efeito do tempo de amamentação exclusiva e/ ou predominante relacionado com o sexo dos lactentes (total, sexo feminino e masculino);

Essas análises estatísticas e descritivas dos mesmos foram realizadas com o intuito de proporcionar maior interpretação dos resultados encontrados durante a pesquisa.

\section{RESULTADOS}

Do total de 46 lactentes estudados, 30 (78,26\%) lactentes estavam sendo amamentados de forma exclusiva e/ou predominante por um período de 6 meses de idade (considerado ideal pela Organização Mundial de Saúde) ${ }^{3}$, e 16 (34,78\%) lactentes não estavam sendo submetidos ao aleitamento materno exclusivo e/ou predominante pelo período de tempo necessário, ou estavam sendo amamentadas de forma mista e/ou artificial (Tabela 1).

Dos 22 lactentes do sexo feminino com aleitamento não exclusivo, cinco $(62,50 \%)$ apresentaram timpanometria normal e $03(37,50 \%)$ alterada. Enquanto que dos com aleitamento exclusivo, 12 $(85,71 \%)$ apresentaram timpanometria normal e dois (14,29\%), alterada (Tabela 2$)$.

Dos 24 lactentes do sexo masculino com aleitamento não exclusivo, três (33,33\%) apresentaram timpanometria normal e seis $(66,67 \%)$, alterada. Enquanto que dos com aleitamento exclusivo, 15 $(100,00 \%)$ apresentaram timpanometria normal e zero $(0,00 \%)$ alterada (Tabela 3$)$. 
Tabela 1 - Números de lactentes amamentados de forma exclusiva e não exclusiva relacionados com a normalidade da timpanometria

\begin{tabular}{lccc}
\hline Forma de aleitamento & $\begin{array}{c}\text { Timpanometria } \\
\text { Normal }\end{array}$ & $\begin{array}{c}\text { Timpanometria } \\
\text { Alterada }\end{array}$ & Totais \\
\hline Não exclusivo & $08(50,00 \%)$ & $08(50,00 \%)$ & 16 \\
Exclusivo & $27(90,00 \%)$ & $03(10,00 \%)$ & 30 \\
\hline Totais & 35 & 11 & 46 \\
\hline
\end{tabular}

Teste Exato de Fisher bilateral: $p=0,0084^{\star}$

Tabela 2 - Número de lactentes do sexo feminino relacionados ao tempo de amamentação exclusiva e/ou predominante e não exclusiva com alterações timpanométricas

\begin{tabular}{lccc}
\hline Forma de aleitamento & $\begin{array}{c}\text { Timpanometria } \\
\text { Normal }\end{array}$ & $\begin{array}{c}\text { Timpanometria } \\
\text { Alterada }\end{array}$ & Totais \\
\hline Não exclusivo & $05(62,50 \%)$ & $03(37,50 \%)$ & 08 \\
Exclusivo & $12(85,71 \%)$ & $02(14,29 \%)$ & 14 \\
\hline Totais & 17 & 05 & 22 \\
\hline
\end{tabular}

Teste Exato de Fisher bilateral: $p=0,3089$

Tabela 3 - Números de lactentes do sexo masculino relacionados ao tempo de amamentação exclusiva e/ou predominante e não exclusiva com alterações timpanométricas

\begin{tabular}{lccc}
\hline Forma de aleitamento & $\begin{array}{c}\text { Timpanometria } \\
\text { Normal }\end{array}$ & $\begin{array}{c}\text { Timpanometria } \\
\text { Alterada }\end{array}$ & Totais \\
\hline Não exclusivo & $03(33,33 \%)$ & $06(66,67 \%)$ & 09 \\
Exclusivo & $15(100,00 \%)$ & $0(0,00 \%)$ & 15 \\
\hline Totais & 18 & 06 & 24 \\
\hline
\end{tabular}

Teste Exato de Fisher bilateral: $p=0,0006^{*}$

- história familiar de perda auditiva na infância;

- suspeita dos familiares de atraso no desenvolvimento de fala, linguagem e audição;

- otite média recorrente ou persistente, com efusão por pelo menos três meses;

- neonatos (recém-nascidos) que ficaram mais de 48 horas na UTI neonatal;

- infecções no período neonatal, tais como: sífilis, toxoplasmose, rubéola, citomegalovírus e/ou herpes;

- infecções no período pós-natal associadas a perdas auditivas sensorioneurais, incluindo a meningite;

- anomalias craniofaciais incluindo as alterações morfológicas de pavilhão auricular e meato acústico externo;

- hiperbilirrubinemia com exsanguíneo-transfusão;

- ventilação mecânica por período > 5 dias;

- síndromes associadas a alterações auditivas;

- desordens neurovegetativas ou neuropatias sensório-motoras.

Figura 1 - Fatores de risco para a Deficiência Auditiva segundo o Joint Committe on Infant Hearing (2000) 


\section{DISCUSSÃO}

Nos últimos anos, vários estudos foram desenvolvidos sobre o leite materno, suas vantagens, sua composição e sua importância para o desenvolvimento infantil saudável ${ }^{5,13,14}$, sendo que a partir dessa premissa resolveu-se verificar influência sobre os tipos de aleitamento, relacionado-os à normalidade das curvas timpanométricas. Os resultados desta pesquisa puderam promover tais indagações, acerca da prática avaliação auditiva em lactentes, além de produzir outras questões sobre tipos e tempo de aleitamento.

É inegável a importância do aleitamento materno na nutrição das crianças, bem como da imunização de vias aéreas superiores e orelha média, entre outros, sendo consenso que o aleitamento materno exclusivo, principalmente nos primeiros seis meses de vida, seja a forma mais adequada e ideal para se alimentar uma criança, suprindo todas as suas necessidades nutricionais para que mantenha seu desenvolvimento dentro da normalidade nesse período ${ }^{5,15,16}$. Neste trabalho verificou-se que o aleitamento materno exclusivo por um período mínimo de seis meses evidenciando a relação da amamentação com a proteção para as alterações timpanométricas.

Estudos têm demonstrado que o leite materno possui a capacidade de inibir o crescimento de vários tipos de bactérias, tendo importante papel contra a colonização bacteriana nasofaríngea e conseqüentemente contra a instalação de processos infecciosos de orelha média ${ }^{17}$. Na presente pesquisa pôde-se averiguar que realmente os lactentes amamentados com leite materno, tanto exclusivo, como predominante, apresentaram menos alterações timpanométricas que os lactentes com amamentação artificial. Quanto ao tempo de aleitamento materno, a maioria dos bebês amamentados de forma exclusiva (nos sujeitos de pesquisa até os 6 meses de idade) ou predominante, 30 dos 46 bebês, foi um fator positivo, pois a pesquisa realizada pelos autores acima citados, obtiveram aleitamento em suas crianças e por menos tempo, inferior a quatro meses.

Pôde-se verificar também, embasados pelos dados da literatura consultada e pelos resultados obtidos neste trabalho, que embora o aleitamento materno seja um processo biológico, seus modelos de aprendizagem e manifestações são de origem social ${ }^{18}$. Por isso, para ser bem sucedida nessa prática, a mulher necessita do apoio da sociedade, uma vez que esta é de grande importância ao desenvolvimento humano de maneira geral. Cabe ressaltar, mesmo não sendo um dos objetivos deste trabalho, que as mães são bem orientadas, uma vez que recebem palestras de cuidados com a higiene de seu filho e incentivo ao aleitamento materno durante as palestras iniciais realizadas pelo programa de atendimento da Bebê Clínica.

A partir dos achados deste trabalho reforça-se a importância da avaliação auditiva em todos os lactentes com o intuito de prevenção e identificação precoce das alterações auditivas pelas conseqüências que estas podem trazer ao desenvolvimento global de uma criança. Atenção especial deve ser direcionada aos bebês que tiveram como via de alimentação o aleitamento não exclusivo, por ter apresentado, neste trabalho, um percentual maior de alteração na timpanometria quando comparados aqueles de aleitamento exclusivo.

É importante ressaltar que grande número de lactentes que vêm sendo acometido de tais alterações, o desconhecimento do problema pelos pais, os danos no desenvolvimento geral e a facilidade das triagens timpanométricas, como os fatores de relevância para a elaboração de um programa contínuo e eficaz de prevenção e detecção de alterações timpanométricas em lactentes.

A partir da literatura averiguada pode-se constatar que realmente o aleitamento materno exclusivo é um importante fator de proteção contra as infecções das vias aéreas superiores, sendo possível que a interrupção precoce do aleitamento materno induza a efeitos adversos no desenvolvimento do sistema imunológico na primeira e segunda infâncias, e conseqüentemente otite média aguda recorrente, adenotonsilite de repetição, rinossinusite infectoalérgica e hiperplasia adenotonsilar ${ }^{19}$. Este trabalho vem a contribuir para esta afirmativa uma vez que na população estudada o aleitamento materno serviu de fator protetor as alterações timpanométricas sugestivas de mudanças na integridade do sistema tímpano-ossicular.

\section{CONCLUSÃO}

Os aleitamentos maternos, exclusivo e predominante, apresentaram-se no estudo como fatores que devem ser levados em consideração, uma vez que houve diferença estatisticamente significante $(p=0,0084)$ nos achados de alteração timpanométrica em lactentes amamentados por mais tempo, mostrando-se este aleitamento como fator protetor para as alterações auditivas referentes a condução do som na população estudada.

A partir disto, quando se pensa em prevenção de alterações auditivas nos primeiros meses de vida, deve-se encorajar o aleitamento materno. 


\begin{abstract}
Purpose: to check the timpanometric findings in six-month-old infants, who were exclusively and/ or predominantly breast fed. Methods: 46 six-month-old infants were studied. From this total, 30 $(61.22 \%)$ of the infants were submitted exclusively to breast feeding during six months and $16(34.78 \%)$ infants were not submitted to exclusive breast feeding. The infants were submitted to external acoustic meatho and eardrum inspection. Results: there were statistically significant $(p=0.0084)$ differences in the findings for timpanometry alterations in breast fed infants for a longer time period. Considering the infant's gender related to breast feeding period, only the male infants presented statistically significant $(p=0,0006)$ results related to normal tympanometric curve protection. Concerning other analyzed factors, it was possible to find a relation between exclusive breast feeding period and tympanometric alterations. Conclusion: despite other risk factors, exclusive breast feeding for a period of six months is the ideal way for breast feeding and it acts as an important factor to prevent tympanometric alterations. It is not necessary to insert other types of food before this period which has been recommended to be an ideal breast feeding period by the World Health Organization.
\end{abstract}

KEYWORDS: Breast Feeding; Ear, Middle; Otitis; Infant

\section{REFERÊNCIAS}

1. Goldman AS. Evolution of the mammary gland defense system and the ontogeny of the immune system. J Mammary Gland Biol Neoplasia. 2002; 7(3):277-89.

2. Lamounier JA, Moulin ZS, Xavier CC. Recommendations for breastfeeding during maternal infections. J Pediatr. 2004; 80(5 Suppl):S181-8.

3. Organização Mundial de Saúde (OMS). Proteção, promoção e apoio ao aleitamento materno: papel especial dos serviços materno-infantis. Genebra: OMS; 1989.

4. Giugliani ERJ. Amamentação: como e porque promover. J Pediatr. 1994; 70(3):138-51.

5. Hoppu U, Kalliomäki M, Isolauri E. Maternal diet rich in saturated fat during breastfeeding is associated with atopic sensitization of the infant. Eur J Clin Nutr. 2000; 54(9):702-5.

6. Marchiori LLM. Analise das alterações auditivas em escolares com queixa de problemas de aprendizagem. Fono Atual. 2002; 21(3):10-5.

7. Melo JJ, Marchiori LLM, Krelling KCA. Prematuros extremos no segundo ano de idade corrigida e curva timpanométrica do tipo B. v. 26. Londrina: Semina; 2005. 74 p.

8. King FS. Como ajudar as mães a amamentar. Londrina: Associação Médica de Londrina; 1997.

\section{RECEBIDO EM: 16/04/2007}

ACEITO EM: 19/11/2007

Endereço para correspondência:

Av. Rio de Janeiro, 1389, ap. 101

Londrina - PR

CEP: $86010-160$

Tel: (43)33232558 / (43)99437571

E-mail: juliana.melo@unopar.br
9. Maranhão HS. Diarréia aguda: aspectos clínicoepidemiológicos, evolução nutricional em lactentes na cidade do Natal, nordeste do Brasil. [doutorado]. São Paulo (SP): Universidade Federal de São Paulo; 2001.

10. Joint Committe on Infant Hearing. Year 2000 position statement: principles and guidelines for early hearing detection and intervention programs. Am J Audiol. 2000; 9(1):9-29.

11. Jerger J. Clinical experience with impedance audiometry. Arch Otolaryngol. 1970; 92(4):311-24.

12. Katz J. Tratado de audiologia clínica. 3. ed. São Paulo: Manole; 1989.

13. Carvalho ABR, Brito ASJ, Thomson Z. Crescimento de crianças alimentadas com leite materno exclusivo. J Pediatr. 1992; 68(9):328-34.

14. Marchiori LLM et al. Aleitamento materno e posição de amamentação como fatores de alterações auditivas em lactentes. J Paranaense Pediatr. $2001 ; 2(4): 13$.

15. Duncan B, Ey J, Holberg CJ, Wright AL, Martinez FD, Taussig LM. Exclusive breast-feeding for at least 4 months protects against otitis media. Pediatrics. 1993; 91(5):867-72.

16. Marques R, Lopez F, Braga J. O crescimento de crianças alimentadas com leite materno exclusivo nos primeiros 6 meses de vida. J Pediatr. 2004; 80(1):99-105.

17. Cruz OLM, Souza MMAS, Alvarenga EL. Estudo clínico com otite média aguda de repetição. Rev Bras Otorrinolaringol. 1998; 5(3):92-5.

18. Hardy EE, Osis MJD. Mulher, trabalho e amamentação: legislação e prática. Campinas: Editora da Unicamp; 1991.

19. Sousa CS, Castro NP. Estudo comparativo de pacientes com queixas otorrinolaringológicas versus aleitamento materno. Acta ORL. 2007; 25(2):128-30. 